\title{
Quiescence, Query, Quandary, Quietus: Public Services in the Library of the Future
}

\section{Henry Snyder}

This paper considers the future library from standpoints of academic administrator and scholar. As the former, what will be the cost of the new services? The latter sees a knowledge explosion occurring in own lifetime. Humanists are still not adjusted to the new environment. In terms of technological revolution many parts of the library are still unchanged. Librarians must help them stay informed about new developments in their respective disciplines and teach them new technologies to access material.

s one considers the demands that users will place upon university libraries within the next two decades, the only thing we can be sure about is that the environment and the demands will be different. Some factors will remain the same. Librarians will continue to be called upon to serve a diverse public - the new freshman, the advanced graduate student, the professor, the staff member, the general public. These patrons may not bring any greater expertise about accessing traditional library resources. But they may be expected, increasingly, to be computerliterate-however that term may be defined. Today I want to suggest what services librarians may be expected to provide. I will speak from the point of view of a teacher, a scholar, a university administrator-and as the manager of a large database.

I think that we may take as a given that every faculty member, every clerical staff member, and probably most students will have personal computers. Certainly everyone will have full access to one. We may take as a second given that through telephone lines, local area networks, or some more sophisticated means, they should be able to enter the systems where the data they seek reside. They will also be able to query libraries online. By 2000 we may be in an environment where librarians never see their clients-or at least not those who want access to information that is stored electronically.

In my university the library offers formal classes for undergraduates on the use of the library. I suspect such instruction may be even more necessary when the library's processes are managed through a computer. The present proliferation of systems designed for libraries suggests the need for an orientation session for each new student, faculty member, and employee on how to use the catalog, order books, use interlibrary loan, or order tele-

Henry Snyder is dean of the College of Humanities and Social Sciences at the University of California, Riverside, California 92521. This article was presented in its original form at a seminar sponsored by the Research Libraries Group in November 1985 at Conoco's Purple Sage Ranch in Bandera, Texas, through the hospitality of Conoco Inc. 
print, perhaps from his or her own personal printer. Advanced classes should be conducted for accessing information outside the campus via a terminal. They should probably be organized by general area-humanities, social sciences, life sciences, and physical sciences. The firstnamed group, in particular, has very different needs. Guides, classes, and training sessions will become an ever more important library responsibility.

I manage a large bibliographical database, the Eighteenth Century Short Title Catalogue. It currently contains nearly two hundred thousand records and eventually should double in size. Many of the items exist in only a few copies, sometimes only one reported, widely scattered over the globe. All too few of the scholars for whom it is intended are aware of the database's existence (that is my problem) or, if aware, have no conception of how to use it. This is a wholly new way of conducting research for them. It is an extraordinary file accessed by search mechanisms of great power. Now that the texts themselves are being made easily available through an enterprising, parallel, microfilming project, they are potentially available to every scholar in their homes or libraries. This can revolutionize scholarship. How are we to make my file a basic tool for scholars, bibliographers, and catalogers? Librarians can run searches for them, if they discover it, as they do for other files. But ultimately all individuals must learn to access it for themselves. Those readers must also become a part of the technological revolution.

Training will need to be conducted on the local computing environment outside the library. What programs are available to the user? What are the best ones for the task in which the user is engaged? Can they be downloaded to the individual personal computer, or are they available by disk from the library? Will the library lend programs as well as books? Will there be terminal rooms just as there are now study halls and carrels? Who will assist the student or professor in selecting the proper kind of format for the final product? Will the library have a graphics- and textprocessing center for producing special copy? Is this a library function? What will distinguish the task of the computer center from the library's?

As an administrator, I must be concerned about cost. How much of the training, the use of equipment and software, the access to off-campus databanks, and the databank time will the library absorb? What about interlibrary loan? Surely the readers ought to have direct access to RLIN or OCLC files in order to search for titles. If they do, should they not also be able to order the items directly? It would save time and labor. But how could libraries manage such a system, given the current protocols, priorities, and restrictions governing loans? Or will this become a moot point, with electronic transmission of texts and/or the creation of central databases of text? Would the readers be billed?

The new environment is going to be an incredibly expensive one by any standard of the past or present. How do we maintain economy and still provide maximum service? What kind of search will elicit the information one requires from a databank in the quickest and most economical fashion? How is this taught? Will the librarian continue to be an intermediary conducting the actual search? Who will determine the limits of what can be requested? We all know how physicists can tie up an entire university computer for an extended period of time with their calculations, given half a chance. Will time limits of some kind be placed on searches? Can relevant portions of databanks be downloaded to a minicomputer for class use? For most purposes, the library is now a free service. Even interlibrary loan is often free. How long can that continue?

The library, like all institutions, is or will be profoundly affected by the technological revolution that characterizes our age. Yet though we have the technical marvel of a MARC, an OCLC and an RLIN, are we sometimes misled by overestimating the extent to which this revolution has engulfed the library? The library is one of the oldest institutions of our civilization. The revolution of movable type and printing supplemented by the rotary press was the only major change in the production of raw materials for the library in five centu- 
ries. Card catalogs were merely more efficient and costly replacements of hand ledgers. Most libraries have now progressed to the point that newer titles are cataloged in a machine-readable file. Checkout is becoming more sophisticated-so much for the current level of automation.

The task of the library is still essentially unchanged after hundreds of years: to secure, preserve, and make accessible the wisdom of humanity as preserved in written, then printed form. On every RLG campus the mission and the means are little changed from those employed by our forebears a century ago. Indeed, the real crisis is that we are being engulfed by, and have not yet learned to cope with, the knowledge explosion of the postwar era. Librarians, as intermediaries between the repository and the user, must find the way to cope.

When I began my career as a historianless than three decades ago-my environment was little different from that of my teacher and his teacher when they commenced their careers. I could create my own basic professional library. Standard works printed in the eighteenth century were still easily acquired. I could receive a catalog, order some books, wait six months, and order again with almost equal success in finding what I wanted still available. Now, all but the newest books have virtually disappeared from the market. Scholars beginning their careers can no longer have their own libraries. They are dependent more than ever on librarians and library resources. The number of individuals in most fields has increased exponentially.

Humanists are traditionally the heaviest library users. Yet the retrieval for new titles and articles is still antediluvian in contrast to many science specializations. Can we not devise some more sophisticated way to inform appropriate readers of the existence of new publications relevant to their work? Should I not be able to call up an index, enter codes to define my interests, and browse online to determine if new publications, especially articles, are of interest to me? Then can I call up the text?

Let me be more specific. It has long been forecast and widely accepted that texts will circulate in forms differing from the traditional printed medium that has been standard from Gutenberg's time to our own. I have suggested that libraries will be increasingly unable to supply printed texts in demand by readers-whether artifacts of the past or some of the flood of new publications that has characterized our world in recent years. Yet readers must have them. The artifacts of the past will be accessible only in some type of reproduction. Even the libraries that possess the originals will determine that their rarity and vulnerability to repeated use prohibits free access to the past. Reproductions must be the answer. Since World War II the preferred format has increasingly been microfilm and, more recently, microfiche. Reprints, the favored medium of the 1950 s and 1960 s, are now too expensive. Microforms raise new problems of access, since often they are not fully cataloged.

Then there are the texts that are themselves available in machine-readable form. I suspect their number will increase rapidly. Surely with all the research being conducted on artificial intelligence, and with the perfection of the optical character reader, we will find it possible to convert texts to machine-readable form quickly, accurately, and cheaply. It may even be possible to make that conversion from microform so that the substantial volume of material now existing in that form can be translated to a more modern storage and reproduction method.

There are many projects in this country to establish database text centers. Oxford University has a model center. To what extent will the titles of the pre-1985 world press be accessible in machine-readable form by 1995 ? How will readers be directed to them? Indeed, how will one be able to master their nature, contents, number, and access so as to be able to impart that information to others? Will data or texts available only in machinereadable form be harder or easier to access? Boolean searches permit analyzing 
the full text in a bewildering variety of ways. Subject indexes will be rendered superfluous by word and phrase searches. But will the database be so monstrous that these searches, theoretically possible, will be rendered impossible because of cost? Or will we have the expertise to design the searches?

As I was writing this paper, I discussed on the same day with three different colleagues the need for a program to evaluate and collate Persian texts; the work of a classicist comparing up to five hundred manuscripts of a given classical text to determine priority, reliability, and similarity; and a Swift scholar's use of the computer to establish definitive texts of his poems. Who is going to identify the databases that contain their texts? Who will advise them on the proper software to carry out the research? Who will train them in the use of the software?

I have been discussing texts and their production. What of the statistical and other databases our colleagues consult? My college maintains membership in the International Consortium for Political Science Research (ICPSR), yet it is consulted by faculty throughout the university and also by users off-campus. Who should maintain these data sets, order new ones, inform the faculty of their existence, and make them accessible to others? Our social scientists are demanding access to ever more data sets of this nature. Who will pay for it? Who will arrange for them, store them, provide access? If the library is an information center, is that not its job? If the work is downloaded to a personal computer, how is that managed and controlled? Can it all be done remotely, without the individual requiring service entering the library?

What about nonstandard, private, or governmental databases, neither created for nor intended for researchers, but obviously of great value. My wife wants to do a study of hospitalized adolescents for her doctoral dissertation. In 2000, will a librarian be able to tell a student what kind of private, confidential databases for studies such as this exist, how they are organized, how they may be accessed, and how they may be downloaded and analyzed? Can we do the same with student records and with court records? Will they all be organized using the same programs or standard courses so that they can be compared?

I hear a lot of talk about electronic mail and bulletin boards. Is this, too, a library function? How are they identified? How are they accessed? Can the library pay an institutional membership or fee so that all members of the institution can access these at will? How are we going to determine and pay access fees and royalties or determine and protect copyrights? By making photocopy machines freely available in libraries, have you already provided an answer?

Several years ago I was working with an English art dealer on the possible purchase of a painting for our university museum. While in The Hague I consulted the files of the National Center for Dutch Art and was able to trace three other versions of the same scene by the same artist, each on a different type of material-copper, cloth, and wood. Why was that information not available from my university library? Will it be in the future? Can I then also order color images, copies of the paintings to enlarge and compare? Will a librarian help me?

I spoke about the antiquated state of libraries today. Books are still stored on shelves by people, paged by people, misshelved by people, vandalized by people, and lost by people. Accessibility to journals is still often limited, during the first months of their residence in our collections, due to the lengthy process by which we segregate and guard them when unbound, then allow them to languish for months in binderies. At the same time we must recognize that the useful half-life of periodicals in some fields is a matter of months rather than years. I assume this is why periodicals are not sent to the bindery the moment all issues that make up a designated volume are received.

Do we distinguish between fields in setting the schedule for the trip to the bindery? Books, too, are often tied up interminably in processing. When processed, 
they are sometimes only brieflisted by untrained clerical help, so that even the minimal records created and inserted in the card catalog are inadequate for retrieving the book. First, LC cards and then central cataloging systems made the creation of cards easier, but there is still the wait for delivery and the use of the postal service, which becomes less rather than more efficient.

When I go to the supermarket, the clerk runs an optical character reader pencil over a bar code on the label, which automatically enters the item description and current price in the register and deletes the item from the store's inventory. A similar unit, linked to the in-house automated catalog, can now be used at the circulation desk for check-in and checkout. But the bar code has to be separately prepared and inserted in each volume. Why do we not insist that publishers include a bar code below each ISBN number on the back of the title page? Why could not a similar unit, reading ISBN numbers linked to RLIN, initiate and even complete the cataloging process for a library?

If we want to borrow on interlibrary loan, recourse to an OCLC or RLIN central data bank speeds the location of a copy, but the notification, manual retrieval, and delivery is the same old, slow process and is subject to all the usual human errors. (So I discovered last month when I received a title similar to but not the same as the one I ordered. I first inquired after the item in July. I was still waiting for it four months later.)

Most journals are read by a very small number of people. The demand for copies of articles is so limited, except for a handful of widely consulted journals, that the National Library of Medicine once informed me that they could and did cut out the article and send it to the requesterthere was so little likelihood of a second query. Increasingly we set type from tape or have access to sophisticated and efficient optical character readers: could not all requested articles or book extracts of twenty-five pages or less be sent by electronic means directly into the requester's home or office? Could not NLM or LC read every roman-type journal into its database and then make these electronically stored texts available by this means?

But I stray from my charge-or my audience. The library may have already solved some of the problems I have described. Certainly librarians are working on solutions. Indeed, I think they must be initiators, not responders. They must help us to solve the crisis that faces our libraries. They must help us identify the problems and establish the priorities for solutions, then enable the users to access the information they need. This task is a daunting one. The library must embrace the new technology and become its exponent. The environment will finally leave the Dark Ages, if not the Stone Age, and become sophisticated and automated to an extent never dreamed of even a decade ago. The heaviest and most demanding library users, the humanists, are the least well trained and the most difficult to train. Librarians must lead us into this new and exciting world. 